\title{
Schools Partnership with Industries Towards Learning Effectiveness in Vocational School
}

\author{
Danny Meirawan \\ Indonesia University of Education, Bandung, INDONESIA \\ dmeirawan@upi.edu
}

\begin{abstract}
This research is to describe the influence of the influence the school partnerships with industry in supporting the effectiveness of learning in the Vocational High School. The method used was explanatory Survey Method with quantitative approach. Data was collected in Vocational Schools in Bandung regency. The study used descriptive and correlation statistical analysis based on the interpretation of the Pearson Correlation which provides the direction and significance. Effectiveness of learning in vocational school in Bandung Regency has a tendency is high, which received contributions from school partnerships with industry and business. Beside that get contributions by other factors, such as leadership, work climate, facilities/infrastructure, motivation, and attitude of students, government policy and others. School partnership with industry than can increase learning effectiveness is collaborative cooperation is not only limited in

coordination. Based on these findings, increasing the effectiveness of learning can be done by improving and strengthening of school partnerships with industry and business.
\end{abstract}

Index Terms - school partnerships, the effectiveness of learning dual system, vocational school.

\section{Introduction}

Link and match policy basically aims to improve the relevance of education with employment needs. This is an attempt to find common ground between the world of education as a producer and the world of work / industry as a consumer. While the basic concept of applying a double system of education itself is providing education that is out systematically integrate educational activities (theory) in schools with educational activities (practices) in the world of business and industrial world.

Education is conducted through a process of working in the world of work will provide the knowledge skills and values work world that is not possible or difficult to obtain at school, among other insights into the formation of quality, superior insight, market insight, insight into the valueadded, and the establishment of work ethic.

Implementation dual system Education in Vocational Schools in Bandung Regency has started since the 1994/1995 school year. In general, Industry and business partnerships with schools in the area of Bandung regency, in line with the development of additional expertise, which opened the program, schools expand the partnership with Industry and business outside Bandung regency.

Dual system Education initial observations on the implementation of some existing vocational school in the Regency Bandung in 2008-2013, found the constraints include: 1) Implementation of industrial working practices (Prakerin) has not achieved the expected results in accordance with the whole concept, 2) not yet implemented an internship program with perfect, 3) is still found in the corporate world and the industrialized world who refuse to accept students perform Prakerin in his company, citing fear of disturbing the productivity of goods / services that is being done by the company, 4) Placement of students in performing Prakerin the company is not in accordance with the competencies expected of expertise 5) Certification of expertise in recognition of the competence of students from the industry is not yet a form of recognition that binds as a guarantee for students to enter employment at the company received six) is still found in less involvement with Industry and business in marketing vocational school graduates to work, 7) absorption vocational school graduates have not yet reached expected results.

These conditions imply that the implementation of the Dual system of education program at a vocational school in Bandung District can be assumed ineffective in observance. Educational institutions can be said to effectively carry out its activities successfully or if the institution can achieve those objectives.

The concept of effectiveness is really a broad concept, covering a number of factors within and outside educational institutions. Effectiveness of this concept by the experts had not yet received the uniformity of views, and in this case because the point of view and approaches undertaken by different disciplines, thus giving birth to different concepts in measurement, such as the mention [1] suggested as follows: "Effective is concerned with doing the Right Things' and relates to out put of the job and what the manager actually achieve, while efficiency is Concerned with 'doing Things Right' and relates to inputs and what the manager does. To be efficient the manager must therefore attend to the input requirements of the job, to clarification of Objectives, planning, organization, direction, and control. But in order to be effective, then the manager must give attention to out put of the job, to Standard and Poor performance in terms of factors as to obtaining best possible result in the Important areas of the organization, optimizing use of resources, increasing in profitability, and Attainment of the aims and Objectives of the organization. Therefore, effectiveness must be related to the achievement of some purpose, objective or task-to the performance of the process of management and the execution of work. "

In this case [1] stressed that the effectiveness is related to the product or output, effectively focus on doing the right thing (doing the Right Things). Managerial in managing the dual system include planning, organizing, implementing, and monitoring will be an impact on improving the quality 
of vocational school graduates. This requires schools and partner institutions / corporate world and the industrialized world to have committed, consistent, and high consistency in the process of Managerial Capability in the dual system Principal effective. To achieve this goal required a partnership between the school and the business world and the industrialized world as a partner institution. Partnerships are required to realize a double-based education program (Dual-Based Program is carried out), especially in the management process, because through the effective management of the dual system goal could be accomplished with either. In the vocational curriculum/ Education Unit Level Curriculum which is a reference and learning activities taught at vocational schools nowadays, the position of the business and industrial world not only as a place to practice (internship) students but also as quality control in the assessment of student learning outcomes with evidence of recognition of the issuance of certification by the industry / professional certification agency.

Business and industrial world (DUDI) as a partner institution of the vocational school is expected to have the commitment, concern and sincerity in the process to produce middle level manpower. To build the commitment and seriousness required of a partnership between the school and the business world and the industrialized world. Partnerships are required in the management of learning is built starting from the understanding, attitude and contribution of the industrial world-the world of work against the school in producing graduates who are oriented to the professional workforce at the secondary level. Partnerships like this can be said as a partnership attitude between the two institutions in producing graduates who are managed collectively and not restricted only as an internship or industrial practice for the learners from the SMK. So the role of partnerships in the Dual system, DUDI starts from the preparation of the program until the assessment and recognition of competence and mastery of learning outcomes undertaken jointly. DUDI also role as a quality control to vocational school. The role is in the form of certification in recognition of certificates of competency issued by the industry / professional certification agency.

Dual system Policy aims to: (1) Produce a quality workforce that is labor that has a level of knowledge, skills and work ethics in accordance with the demands of jobs.(2) to strengthen linkages and relevance between SMK and the world of work, (3) Improve the effectiveness of the process of education and training of qualified manpower. (4) Give recognition and appreciation of work experience as part of the educational process.

Beside that " partnership should be understood in the socio-economic and socio-political context of the recent educational reform" [2]. And Social partnership refers to cooperation among schools, employees, other parties or private sectors to achieve the common aim of improving educational quality" [3].

There are many components that play a role in the Dual system of education where the most direct role includes: the school and the world industrial / business world. Thus the object of research in this study is the school of Managerial Capability in the dual system, partner schools and institutions of the business or industrial world. At school there are learning that prepares students to enter the world of work, besides the industrial world has a system or climate own work is very different from the climate in schools, therefore, very necessary partnership between the schools with the business or industrial world formally and clearly so that there is relevance of what is learned in school with the reality on the world of work.

The problem in this research is the effectiveness of schools that implement Dual system, with the formulation of the problem as follows: "How to influence behavior Partnership Business / Industry of the effectiveness of the Dual system of education?

The general objective of this research is to get a picture of how effectively schools are implementing Dual system, a picture of the partnership business / industry, and see the impact of behavior on the effectiveness of the implementation of partnership Dual system of Education.

\section{Methods}

The research method used in this research is survey method with the correlation approach, where this method is used to find relationships between independent variables and dependent variable. Kind research used survey research, is research conducted using questionnaires as a research instrument for the study sample.

The population in this research is both Head of State or private vocational school in District Bandung, number of population is 67 Vocational School (SMK). The sample amount is $50 \mathrm{SMK}$ which has implemented a comprehensive system of dual education (dual system). Sampling was done purposively.

\section{Results and Discussion}

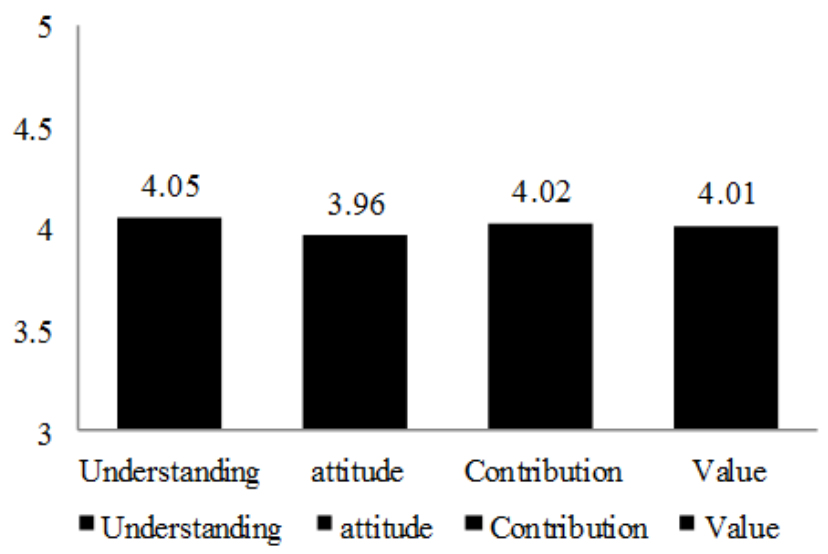

Fig. 1. Behavior of school partnerships with the business/industrial world

\section{Preview of Behavior of school partnerships with the business/industrial world}

Preview Behavior Partnership DUDI at a vocational school in the Environment Department of Education and Culture in Bandung regency is good (4.01 of an ideal score 5). Picture is viewed from the aspect of understanding (4.05), aspects of the contribution (4.02), and the latter is the aspect of attitude (3.96). Picture is visually presented in the fig. 1 . 


\section{Preview Effectiveness of the dual system of Education}

Effectiveness of the dual system description on a vocational school in the Environment Department of Education and Culture in Bandung District, generally show that the effective condition (3.86 of a maximum score 5). This picture is built from the design aspect of the expected (3.98) and target aspects of the program (3.75). These images are visually shown in the figure below;

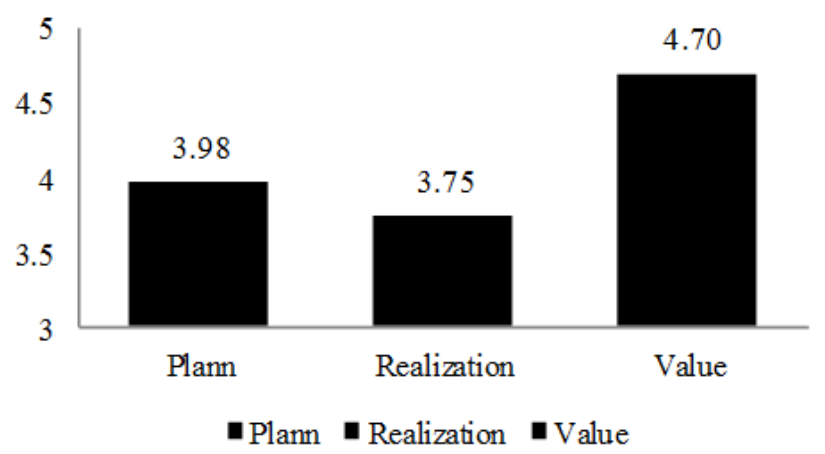

Fig. 2. Dual system of Education Effectiveness

Design aspects of expected, built from the constructs as follows:

Employment needs of both qualitatively and quantitatively, is good, can be interpreted that the DUDI specially invited school principals in the recruitment of labor and work together in alumni marketing in the world of work / industry. When viewed from absorption percentage who graduates each year approximately $50 \%$ and students who perform the practice can be accepted as workers in the world of business / industrial world.

Certification is good. This could be interpreted the parties have been conducting professional associations and the company's competency test gave the opportunity to students to get scholarships to a higher level again, besides that also the certification of the business world doing internships Prakerin and besides doing the certification test competence, which in will ultimately improve the quality of vocational school graduates. Collaboration is also a gateway skill because producing work with others is most challenging skill to require [4].

\section{Influence Behavior Partnership to learning effectiveness in Vocational School}

Based on research findings that there is a strong correlation $(r=0.754)$ with significance at 0.01 , between the behavior partnership of DUDI with the leaning effectiveness. Also obtained, contribution from behavior partnership industry and business with school in understanding and attitude to the effective learning performance is $56.85 \%$. And there are predictions of the regression equation $\mathrm{Y}=29.907+0.406 \mathrm{X}$ (Sig.0, 001). So that it can be said there is significant influence of behavior partnership to the dual system implementation effectiveness.

Behavior partnership proved to be a part of the elements that can influence the effectiveness of the dual system, and therefore to optimize the effectiveness of the dual system can be improved by encouraging partnerships to improve its behavior in understanding the mission and purpose of the dual system program itself. Business / Industrial world that are able to identify the roles and responsibilities as partners will encourage DU DI to give consideration in making revisions or improvements to achieve the goals agreed upon. This is done continuously and is improved will help in enhancing the implementation of dual system as expected.

Business and industrial world that shows the attitude of cooperation in solving problems in the dual system will encourage school principals to do this same thing, so any problems encountered in the implementation of dual system could be minimized. Attitudes that support from the business / industry will be reflected in a willingness to sit together and in an integrated to encourage the changes of academic and non academic atmosphere accompanied by sharing opinions, so that the integration in social and cultural structure will accelerate the achievement of educational goals the Dual system.

Competence in these multiple illiteracies is now a necessary requirement if EFA is to respond to current social and economic demands. TVET is specifically designed to provide access to and competence in these illiteracies because of its focus on technology. Access to productive work is one need, but so are the creative attitudes relevant to seeking and finding work.

The nature of work: Increasingly, work involves skilled tasks, each one requiring specialized knowledge. Workers need not only to obtain the necessary knowledge, but to be able to co-operate with others in applying it [5].

\section{Conclusions}

Behavior of Partnership Business/Industry world in Bandung regency, significantly affect to the Effectiveness of the dual system of Education implementation with the contribution is $56.85 \%$. In other words Behavior Partnership determined the Effectiveness of the dual system of Education amounted to $56.85 \%$ while the rest is determined by other factors, such as leadership, facilities and infrastructure, educators, financing, etc.

Effectiveness of the Dual System in SMK in Department of Education and Culture in Bandung regency in general, is high. Effectiveness of the Dual System of Education is measured from the dimensions: a) Design the expected and b) Target Program. Design aspects are expected to occupy high positions, especially in the indicators to improve the quality of vocational school graduates with very good, but when viewed in detail shows that the lowest position shown by the indicator instilled strong community relations.

Dual system effective performance driven by the behavior of the partnership industry with school will assist in target achievement for dual system program, especially in improving the professional quality of students, characterized by increasing their skills and professional expertise as a result of industry practice or internship education. With the achievement of academic competence (professional skills) and non-academic (e.g., discipline and responsibility) through an internship program in industry indicates that a high behavior partnership to support the dual system goal achievement for the school itself and the behavior of such partnerships provide satisfaction because of their graduates have more secure and meaningful knowledge. 
Behavior of Partnership Business/Industry world in Bandung regency, significantly affect to the Effectiveness of the Dual System of Education (PSG) implementation with the contribution is $56.85 \%$. In other words Behavior Partnership determined the Effectiveness of the Dual System of Education amounted to $56.85 \%$ while the rest is determined by other factors, such as leadership, facilities and infrastructure, educators, financing, etc. The recommendations from this research include the following:

To improve the effectiveness of PSG can be started from the build Behavior Partnership Business /Industry world. In building partnerships behavior should attempt to further improve the attitude aspect perpetrators DU/DI on the implementation of vocational learning in an atmosphere that encourages academic and non academic. Innovative attitude is necessary in the face of change and challenge, especially challenges to the era of World Business / World Industries involved in the Partnership. In Partnership of Business / Industry world is not only a role as a partner that provides real-life experience to students facing real atmosphere within the scope of work but are actively involved in encouraging a change in atmosphere of academic and non academic students who are involved in the Dual System of Education program, for it some things you can do are:

Thoughts contributed by instructors / mentors from the industry in determining the academic load that has relevance to the increased professionalism of students in accordance with company standards / industry someday when they go into the field after SMK.

Creating a fully competitive conditions but walked with such a positive assessment of the format that encourages every student involved Dual System of Education to continue improve of ability student both academic and non academic.

New rule stipulating that challenges students to improve their personal qualities through good discipline against time or against a given task.

Effectiveness of the Dual System of Education program at Bandung Regency is high. However, some indicators need to increase and improve, like; employment needs of both quantitatively and qualitatively, certification, marketing and percentage of absorption is not optimal, the lack of recognition and appreciation of the overall business / industrial world of work experience. Some things you can do are:

The cooperation between the World Business /World Industrial and schools in establishing graduate qualification standards in accordance with general standards of the company / industry as a user. Schools and the World Business /Industry can cooperate in making preparation learning programs which appropriate with demands and needs in the field.

Lack of recognition and appreciation of this work experience can be improved or enhanced by analyzing the periodic competency test, where the result of competency test will be the feedback to schools and industrial world.

Behavior of school partnerships with business/industrial world has a significant influence to the Effectiveness of the Dual System of Education. These results show the reality on the ground proved that the behavior of the school partnership to give effect to the
Effectiveness of the Dual System of Education. Some things you can do are:

Provide opportunities and more opportunities for the World Business / World Industries as a partner to become actively involved by organizing programs Dual System of Education challenging and interesting, and provides benefits for both parties.

Establish a forum / special containers between the World Business / World Industries and the school to sit down together at the beginning of each school year in order to increase mutual understanding about the Dual System of Education program in a comprehensive manner.

Giving awards from the government in the form of "reward" to the World Business / World Industries has been actively helping the school (SMK) in the implementation of the dual system of education, such as tax holiday and so forth.

\section{References}

[1] Rukmana DW,. (2006) Strategic Partnering Model Manajemen Pendidikan Berbasis Kemitraan., Bandung, Alfabeta.

[2] Kim, D dan Jeong, M.K (2004) Insufficient partnership, ineffective foreign aid, and public education in Laos. KEDI Journal of Educational Policy - 10 (1) (2013) hlm. 173-193

[3] Laid , M. dan Lo, L.N.K. (2006) Decentralization and Social Partnership: The Development of Vocational Education at Shanghai and Shenzhen in China. Educational Research for Policy and Practice ( 5) hlm. 101-120

[4] Jacobson, Vera (2013), Communication, Collaboration and Credibility: Empowering Marginalized Youth With 21st Century Skills. International Journal of Vocational Education and Training, vol. 21. Number 2, 2013. P 24 - 36

[5] Hughes, Phillip (2005), Controversies: Why Access To TVET For All IS Essential IF Education For All Is To Be Achieved, Journal PROSPECTSIVolume 35, Issue 3, September 2005\art-3A10.10072Fs11125-005-4263-3.pdf 